\title{
Epidemiologi, utredning og behandlingsindikasjon ved aortaaneurisme
}

\author{
Sammendrag \\ Bakgrunn. Ruptur av aortaaneurisme \\ er en livstruende tilstand - ubehandlet \\ er utgangen dødelig. Diagnosen er \\ vanskelig å stille klinisk. Her gis en \\ oversikt over epidemiologi, utredning \\ og behandlingsindikasjon for pasienter \\ med aortaneurisme.
}

Materiale og metode. Oversiktsartikkelen er bygd på forfatterens kliniske erfaring og på ikke-systematiske søk i PubMed.

Resultater. Mannlig kjønn, høy alder og røyking er dominerende risikofaktorer for utvikling av aortaaneurisme. Ikkerumpert aortaaneurisme kan avdekkes ved ultralyd-eller CT-undersøkelse. CT-undersøkelse kan med høy treffsikkerhet avgjøre om det foreligger ruptur. En maksimal aneurismediameter på $5,5 \mathrm{~cm}$ eller en vekstrate på mer enn $10 \mathrm{~mm}$ på ett år regnes som behandlingsindikasjon. 30-dagersmortaliteten etter kirurgi er ca. $5 \%$ når tilstanden opereres elektivt, men det er fortsatt høy dødelighet ved kirurgi for ruptur (20-40\%). Den totale mortaliteten ved rumpert aortaaneurisme, dvs. summen av dem som dør uoperert og dem som $\mathrm{d} ø \mathrm{r}$ i forbindelse med/etter operasjon, er beregnet til å være opp mot $90 \%$. Screeningprogrammer for abdominale aortaaneurismer kan redusere dødeligheten med $58 \%$, fordi en større andel da vil bli operert elektivt.

Fortolkning. Pasienter med aortaaneurisme må følges opp hos fastlege for god blodtrykksregulering og hjelp til røykeslutt. Mortaliteten er fortsatt høy ved rumpert aortaaneurisme. Det er derfor igangsatt screeningprogrammer for abdominale aortaaneurismer i USA, Storbritannia, Danmark og Sverige, og slike programmer bør innføres også i Norge.

\author{
Jarlis Wesche \\ jarlis.wesche@ahus.no \\ Avdeling for kar- og thoraxkirurgi \\ Akershus universitetssykehus \\ 1478 Lørenskog
}

«Aneurisme» kommer fra det greske verbet «aneurynein», som betyr «å utvide». Et abdominalt aortaaneurisme er en utposning på hovedpulsåren som gir minst $50 \%$ økt diameter (1). En mer praktisk definisjon som brukes ofte er aortadiameter $>30 \mathrm{~mm}$ (2). Figur 1 er en fremstilling av kartreet $i$ abdomen med aortaaneurisme. Ruptur av aneurismet gir blødning ut i omgivende vev og medfører en livstruende tilstand hos pasienten - ubehandlet er utgangen dødelig (fig 2). Det er beregnet at om lag $1-2 \%$ av dødsfallene $\mathrm{i}$ den vestlige verden skyldes rumpert aortaaneurisme (3). Tilstanden kan utvikle seg i hele aorta, men er hyppigst forekommende i infrarenale abdominalaorta. Data i denne artikkelen vil derfor vesentlig omhandle abdominalaorta med eller uten involvering av iliakalkar.

Diagnosen stilles oftest tilfeldig i forbindelse med utredning for andre lidelser, som abdominal- og rygglidelser. Åpen operasjon med eksklusjon av aneurismet ved innsying av kunstprotese ble innført i 1950-årene. Dette var standardoperasjonen inntil 1990årene, da endovaskulær behandling med innsetting av stentgraft (metallforsterket protese) via tilgang i lyskene ble innført. Stentgraftbehandling av abdominale aortaaneurismer utføres i dag ved alle landets universitetsklinikker. Fortsatt opereres over halvparten av aneurismene med åpen teknikk, vesentlig pga. begrensninger $\mathrm{i}$ den endovaskulære metoden.

Hensikten med denne artikkelen er å gi en oppdatert oversikt over epidemiologi, utredning og behandlingsindikasjon for pasienter med aortaneurisme.

\section{Materiale og metode}

Denne artikkelen bygger på egen erfaring og på ikke-systematiske søk i PubMed.

\section{Epidemiologi, etiologi og risikofaktorer}

Aortaaneurisme forekommer 2-6 ganger så hyppig hos menn som hos kvinner. Antallet som utvikler aortaaneurisme øker med alderen, spesielt fra 50 års alder hos mennene, ti år senere hos kvinnene (4-6).

I en svensk studie fant man aortaaneurisme hos $16,9 \%$ av mennene og hos 3,5\% av kvinnene i alderen 65-75 år (4). I Tromsø-undersøkelsen fra 2001 var tallene noe lavere ( $8,9 \%$ for menn og 2,2\% for kvinner), men her var også yngre personer inkludert, undersøkelsen omfattet aldersgruppen 25-84 år (5). Studier viser at forekomsten av aortaaneurismer øker i befolkningen og at økningen er større enn det som kan forklares med økende antall eldre i samfunnet (6).

Årlig opereres 700-800 pasienter for aortaaneurisme i Norge, flest menn. (7). Det er ca. $5 \%$ 30-dagersdødelighet hos dem som blir behandlet elektivt, åpent eller endovaskulært (miniinvasivt), mens det fortsatt er høy dødelighet $(33,7 \%)$ hos dem som blir operert for rumpert aortaaneurisme $(7,8)$. Dertil kommer de som dør utenfor sykehus, noe som gir en totaldødelighet på $60-90 \%$ for rumpert aortaaneurisme (8).

Etiologien bak utviklingen av aortaaneurisme er ikke endelig kartlagt, men man vet at mange faktorer er involvert. Såkalt degenerative aortaaneurismer utgjør over $90 \%$. Mindre hyppige årsaker er infeksjoner, arvelige bindevevslidelser (f.eks. Marfans sykdom), arteritter, traumer og pseudoaneurismer etter tidligere aortakirurgi eller aortadisseksjon.

Følgende faktorer er assosiert med økt risiko for utvikling av aortaaneurisme: høy alder, mannlig kjønn, røyking, hypertensjon, hjerte- og karsykdom og positiv familiehistorie $(4-6,9,10)$. Flere studier $(5,9)$ viser at røyking er den faktoren som er sterkest assosiert med utvikling av aortaneurisme, noe man også fant i den nylig publiserte sjuårsoppfølgingen i Tromsø-undersøkelsen (11). Familiær opphopning er godt dokumentert i litteraturen, med økt forekomst hos første-

\section{Hovedbudskap}

- Aortaaneurisme forekommer hyppigst hos røykende menn over 60 år

- Diagnosen abdominalt aortaaneurisme er vanskelig å stille klinisk, men tilstanden kan avdekkes ved ultralyd- eller CT-undersøkelse

- CT-undersøkelse kan avgjøre om det foreligger ruptur

- Behandlingsindikasjon er maksimaldiameter på 5,5 cm eller årlig vekstrate over $10 \mathrm{~mm}$ 
gradsslektninger av begge kjønn (15-25\%). Disse slektningene utvikler aneurisme i yngre alder enn det som er vanlig (10). Brødre i slike familier kan ha hele 18 ganger økt risiko for å ha aortaaneurisme. Man bør derfor ha lav terskel for å henvise slike førstegradsslektninger til undersøkelse.

Det er også verdt å merke seg at de som har abdominale aortaaneurismer, oftere også har aneurismer i andre deler av aorta og underekstremitetsarterier som a. poplitea. Preoperativ utredning av slike pasienter bør også omfatte torakal- og poplitealkar.

De fleste aneurismer øker i størrelse, og størst årlig vekstrate har de store aneurismene (10). Vekstraten er ca. $10 \%$ per år for aneurismer $<4 \mathrm{~cm}$ i diameter, men det er betydelige individuelle variasjoner. Kvinner synes å ha høyere vekstrate enn menn $(12$, 13). Det er økt vekstrate hos hypertonikere og hos røykere (14). Hypertoni øker også faren for ruptur.

\section{Utredning}

Aortaneurismer kan presentere seg med symptomer som ruptur, trombose, embolisering, kompresjonssymptomer fra naboorganer, som duodenum, ureter eller vena cava, som usur av columna eller med generelle symptomer som sepsis (infeksiøse aneurismer). Iblant kan pasientene fortelle at de kjenner noe pulsere i abdomen.

Men langt de fleste aortaaneurismer er asymptomatiske, noe som vanskeliggjør diagnosen. Ved klinisk undersøkelse alene er den positive prediktive verdien for å oppdage et aneurisme $>3,5 \mathrm{~cm}$ ved bukpalpasjon bare $15 \%$ (15). Diagnosen blir oftest stilt tilfeldig fordi det blir utført bildediagnostiske undersøkelser for lidelser i abdomen eller hofte/rygg. Disse undersøkelsene er oftest abdominal ultralyd, CT- og MRundersøkelser, av og til oversiktsrøntgen av abdomen hvor kalk i aortaveggen kan ses.

Ultralyd er en rask, ufarlig og billig undersøkelse som er velegnet til diagnostikk og kontroll av aortaaneurismer frem mot behandling, og den brukes ved screeningprogrammer. Den kan som hovedregel ikke avgjøre om det foreligger ruptur. Det kan raskt avklares med høy treffsikkerhet ved CT-angiografi. Slik kontrastforsterket spiral-CT er etter hvert blitt hovedmetoden ved diagnostikk og planlegging av operasjon for aortaaneurismer og anses som nødvendig preoperativ undersøkelse ved endovaskulær behandling. Med ulike dataprogrammer kan tredimensjonale (3D) rekonstruksjoner og «utbrettinger» lages for preoperativ planlegging og måltaking til endovaskulære proteser (stentgraft).

Ved MR-undersøkelse unngår man strålingseksponering, men metoden gir ofte mindre informasjon og er mindre tilgjengelig i øyeblikkelig hjelp-situasjoner, samt at den har begrensninger pga. magnetismen. Kontrasten som gis ved CT- og MR-undersøkelser kan være skadelig for nyrene hos pasienter med redusert nyrefunksjon, og gadolinium, som brukes ved fremstilling av blodårer ved MR-undersøkelse, kan utløse nefrogen systemisk fibrose. Angiografi brukes ikke alene i utredning av aneurismer, men kan gi verdifull tilleggsinformasjon og er nødvendig å bruke peroperativt ved endovaskulær behandling.

Når abdominale aortaaneurismer gir symptomer, er det som oftest pga. ruptur eller akutt ekspansjon, såkalt truende ruptur. Pasienter med ruptur får ofte akutte smerter $\mathrm{i}$ abdomen med ev. utstråling bak i rygg/flanke eller hofte/lyske. Ofte er rumperte aortaaneurismer palpable og ømme hvis ikke pasienten er for adipøs. I ca. $20 \%$ av tilfellene skjer rupturen fortil, og pasientene forblør før de rekker å komme til sykehus. Hos de resterende $80 \%$ skjer rupturen med blødning retroperitonealt, noe som gir et begrenset hematom og øker sjansen for overlevelse.

Klassiske symptomer på rumpert aortaaneurisme er hypotensjon, ev. med synkope/ sjokk, abdominalsmerter/ryggsmerter og pulsatil oppfylling i buken. Men slike symptomer forekommer bare hos $25 \%$ av dem med påvist rumpert aortaaneurisme (16). Tidlig diagnose hos pasienter med rumpert aortaaneurisme uten hypotensjon er vanskelig, spesielt gjelder det fete personer. Derfor må man ha tilstanden in mente, spesielt hos eldre med uklare buk- og/eller ryggsmerter. Dersom pasienten er hemodynamisk stabil og har palpabelt aneurisme eller kjent aneurisme, bør vedkommende til CT-undersøkelse snarest for å utelukke ruptur. CT er spesielt verdifullt for å avklare ruptur der det er ømhet ved palpasjon av aneurismet, siden det hos pasienter uten påvist ruptur er økt mortalitet ved akutt operasjon (7). Dersom ikke annen patologisk årsak til smertene avdekkes ved CT, bør slike pasienter stabiliseres/optimaliseres og opereres - helst på dagtid - i løpet av nærmeste døgn. Dersom pasienten har kjent aneurisme og er hemodynamisk ustabil, skal vedkommende til operasjon umiddelbart.

\section{Screening}

Siden aortaaneurisme er en tilstand som oftest diagnostiseres først ved ruptur og de fleste dør før de får behandling, har man størst potensiell gevinst ved å oppdage og behandle aneurismene før de rumperer. Det har derfor vært utført store studier i mange land for å undersøke kostnader og nytte av slik screening med én ultralydundersøkelse rundt 65 års alder (17-21). De har alle konkludert med at screening kan redusere mortaliteten ved aortaaneurisme betydelig, med opptil $58 \%(17,18)$. Et viktig argument mot screening er at man gjør friske mennesker til pasienter og reduserer deres livskvalitet, men ut fra disse undersøkelsene har man ikke funnet holdepunkter for at det er dårligere livskvalitet hos dem som er blitt fulgt i programmene.

En Cochrane-oversikt fra 2007 konklude-

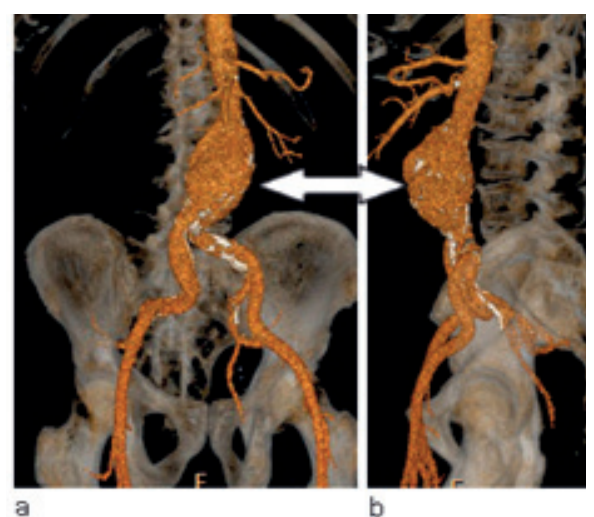

Figur 1 Rekonstruerte CT-bilder med tredimensjonal fremstilling - al front og b) side - av kartreet i abdomen med aortaaneurisme (pil). Foto Billeddiagnostisk senter, Akershus universitetssykehus

rer med at det finnes evidens for signifikant reduksjon i mortaliteten ved å innføre ultralydscreening for aortaaneurismer hos menn i alderen 65-79 år (22). Foreløpig er det ikke påvist tilsvarende for kvinner, men bare i en av studiene i Cochrane-rapporten var kvinner inkludert. Manglende påvisning kan skyldes at andelen røykende kvinner i denne alderspopulasjonen er lavere og at prevalensen hos kvinner vil stige $\mathrm{i}$ fremtiden når dagens store andel unge røykende kvinner blir eldre.

I USA har man innført selektiv screening for kvinner med høy forekomst av aortaaneurismer i nær familie. I Storbritannia er erfaringen at økningen i antall elektive operasjoner screeningen genererer, tas hånd om av eksisterende karkirurgisk service og at antall akutte operasjoner reduseres (23).

\section{Medisinsk behandling}

Pasienter med aortaaneurisme er generelt karsyke og bør få samme medisinske intervensjon for risikoreduksjon som andre pasienter med hjerte- og karsykdom, som røykeslutt, statiner, acetylsalisylsyre og ev.

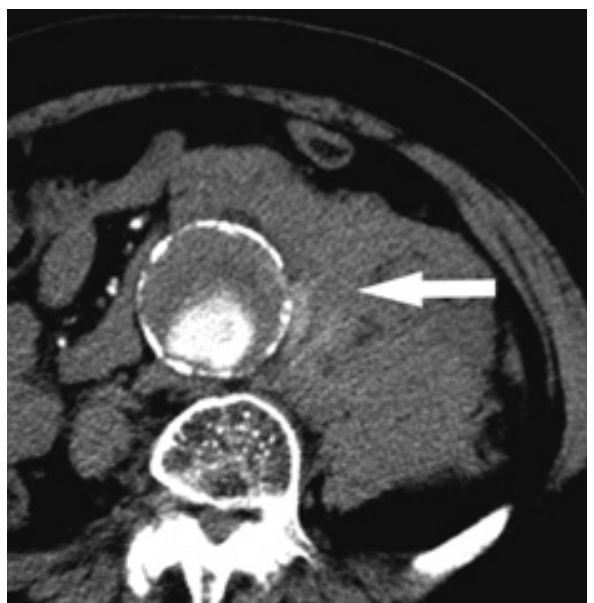

Figur 2 CT-aksialbilde av abdomen med aortaaneurisme med ruptur (pil), pågående blødning og hematom. Foto Billeddiagnostisk senter, Akershus universitetssykehus 
antihypertensiver som ACE-hemmere og betablokkere. Slik behandling er også viktig for å redusere perioperativ risiko. Det finnes per i dag ingen spesifikk medisinsk behandling som kan få aneurismer til å gå tilbake.

\section{Indikasjon for kirurgisk behandling}

I begynnelsen av 1990-årene ble pasienter ofte operert for aortaaneurismer med diameter $<5 \mathrm{~cm}$. De siste ti årene har data fra flere store randomiserte undersøkelser, bl.a. UK Small Aneurysm Trial fra Storbritannia (14) og ADAM Trial fra USA (24), gitt oss pålitelige data om rupturrisikoen for små aneurismer (diameter $4-5,5 \mathrm{~cm}$ ). I begge undersøkelsene var det en lav årlig rupturrisiko på $1 \%$ hos mennesker $\mathrm{i}$ alderen 60-75 år uten alvorlig hjerte- eller lungesykdom. En Cochrane-studie fra 2008 (25) angir en aneurismediameter på $5,5 \mathrm{~cm}$ eller rask vekst (over $10 \mathrm{~mm}$ per år) som behandlingsindikasjon for pasienter med ellers lav operasjonsrisiko.

I andre studier har man funnet at rupturrisikoen er fire ganger høyere hos kvinner enn hos menn $(12,26)$. En lavere aneurismediameter $(50-52 \mathrm{~mm})$ er derfor foreslått som behandlingsindikasjon hos kvinner, samtidig har flere studier vist høyere operasjonsmortalitet enn hos menn. Det er derfor fortsat omdiskutert om man skal anbefale lavere behandlingsindikasjonsgrense hos kvinnene. Slike diametermål er også beheftet med en viss usikkerhet, på 2-5 mm (27), slik at man kan argumentere for at pasienter med aortaaneurismer med diameter i området 5-5,5 $\mathrm{cm}$ bør tilbys operasjon hvis de ellers er rimelig friske (28).

Hos pasienter med familiær opphopning av aortaaneurismer er det også høyere rupturrisiko. Det er også antatt at sakkulære (kulerunde) aneurismer har større rupturrisiko enn de mer spindelformede (fusiforme) med samme diameter, selv om dette ikke er dokumentert.

Vi vet mindre om det naturlige forløpet av store aneurismer, siden de fleste blir operert når de blir diagnostisert. Men vi vet fra autopsistudier at rupturrisikoen er større ved større aneurismer. Dessuten har man i to store studier i de senere år fulgt pasienter med aortaaneurismer med diameter over $5,5 \mathrm{~cm}$ som pga. komorbiditet var bedømt til ikke å tåle stor kirurgi. Disse viser at den årlige rupturrisikoen kan være opptil $25 \%$ for aneurismer over $6 \mathrm{~cm}$ i diameter (29) og over $30 \%$ for aneurismer som er over $7 \mathrm{~cm}$ i diameter (30).

\section{Komorbiditet}

Elektiv operasjon for aortaaneurisme er et profylaktisk inngrep. Behandling for asymptomatisk aortaaneurisme er indisert når risikoen for ruptur er større enn operasjonsrisikoen, men man må også ta hensyn til pasientens leveutsikter og om vedkommende ønsker operasjon. Som relativ kontraindikasjon regnes hjerteinfarkt for under tre måne- der siden, alvorlig hjertesvikt, klaffesykdom, lungesykdom med hviledyspné, nyresvikt og malignitet med kort forventet leveutsikt (29).

Der man mistenker alvorlig komorbiditet, bør pasienten utredes $i$ tett samarbeid med andre spesialister som også har ansvar for vedkommende før man kommer med en anbefaling (anestesiolog, kardiolog, lungelege og nefrolog)

\section{Konklusjon}

Ultralydundersøkelse er velegnet metode til å følge små aortaaneurismer. CT-undersøkelse kan med høy treffsikkerhet avgjøre om det foreligger ruptur av aneurismet. Behandlingsindikasjon er aneurismediameter $>5,5 \mathrm{~cm}$ eller årlig vekst på mer enn 10 mm, men man må ta hensyn til komorbiditet og leveutsikter og om pasienten ønsker operasjon. Man bør ha lav terskel for å henvise personer med kjent familiær opphopning av abdominale aortaaneurismer til utredning.

Pasienter med kjent aortaaneurisme bør ha god oppfølging hos fastlege for medisinsk risikoreduksjon. Spesielt viktig er god blodtrykkskontroll og hjelp til røykeavvenning, da dette er viktige risikofaktorer for $ø k t$ vekst av aneurismet. Hypertensjon øker også faren for ruptur.

Det er lav mortalitet ved elektiv operasjon for abdominalt aortaaneurisme, både åpent og endovaskulært, men den er fortsatt høy ved ruptur. Screeningprogrammer for abdominale aortaaneurismer kan reduseres dødeligheten betydelig. Det er igangsatt screeningprogrammer i USA, Storbritannia, Danmark og Sverige, og slike bør innføres også i Norge

\section{Oppgitte interessekonflikter: Ingen}

\section{Litteratur}

1. Johnston K, Rutherford R, Tilson M et al. Suggested standards for reporting on arterial aneurysms. J Vasc Surg 1991; 13: 452-8.

2. Steinberg I, Stein HL. Arteriosclerotic abdominal aneurysms. Report of 200 consecutive cases diagnosed by intravenous aortography. JAMA 1966 195: $1025-9$.

3. Wilmink TB, Quick CR, Hubbard CS et al. The influence of screening on the incidence of ruptured abdominal aortic aneurysms. J Vasc Surg 1999; 30: $203-8$

4. Wanhainen A, Bjørck M, Boman K et al. Influence of diagnostic criteria on the prevalence of abdominal aortic aneurysm. J Vasc Surg 2001: 34: 229 -35.

5. Singh K, Bønaa KH, Jacobsen BK et al. Prevalence and risk factors for abdominal aortic aneurysms in a population-based study. The Troms $\varnothing$ Study. Am J Epidemiol 2001: 154: 236-44.

6. Bengtsson H, Bergqvist D, Sternby NH. Increasing prevalence of abdominal aortic aneurysms. A necropsy study. Eur J Surg 1992; 158: 19-23.

7. Haug ES, Romunstad P, Sæther OD et al. Quality of data reported on abdominal aortic aneurysm repair-a comparison between a national vascular and a national administrative registry. Eur J Vasc Endovasc Surg 2005; 29: 571-8.

8. Bengtsson $\mathrm{H}$, Bergqvist D. Ruptured abdominal aortic aneurysm: a population-based study. J Vasc Surg 1993; 18: 74-80.

9. Lederle FA, Johnson GR, Wilson SE et al. The aneurysm detection and management screening program: validation cohort and final results. Arch Intern Med 2000; 160: 1425-30.
10. Verloes A Sakhalisahan N Koulischer Let at. Aneurysms of the abdominal aorta: familial and genetic aspects in three hundred thirteen pedigrees. J Vasc Surg 1995; 21: 646-55.

11. Forsdahl SH, Singh K, Solberg S et al. Risk factors for abdominal aortic aneurysms. A 7-year prospective study: The Troms $\varnothing$ Study, 1994-2001. Circulation 2009; 119: 2202-8.

12. Brown PM, Zelt DT, Sobolev B. The risk of rupture in untreated aneurysms: the impact of size, gender, and expansion rate. J Vasc Surg 2003; 37 $280-4$

13. Solberg S, Singh K, Wilsgaard T et al. Increased growth rate of abdominal aortic aneurysms in women. The Troms $\emptyset$ Study. Eur J Vasc Endovasc Surg 2005; 19: 145-9.

14. The UK Small Aneurysm Trial Participants. Mortality results for randomized controlled trial of early elective surgery or ultrasonographic surveillance for small abdominal aneurysms. Lancet 1998; 352: 1649-55

15. Beede SD, Ballard DJ, James EM et al. Positive predictive value of clinical suspicion of abdominal aortic anerysm: implications for efficient use of abdominal ultrasonography. Arch Intern Med 1990, 150: 549-51

16. Marston WA, Ahlquist R, Johnson G jr. et al. Misdiagnosis of ruptured abdominal aortic aneurysms. J Vasc Surg 1992; 16: 17-22.

17. Kim LG, Scott RAP, Ashton HA et al. A sustained mortality benefit from screening for abdominal aortic aneurysms. Ann Intern Med 2007; 146: $699-706$

18. Ashton HA, Buxton MJ, Day NE et al. The Multicentre Aneurysm Screening Study (MASS) into the effect of abdominal aortic aneurysm screening on mortality in men: a randomized controlled trial. ancet 2002: 360: 1531-9.

19. Scott RA, Wilson NM, Ashton HA et al. Influence of screening on the incidence of ruptured aortic aneurysms: 5-year results of a randomized controlled study. Br J Surg 1995: 82: 1066-70.

20. Lindholt JS, Juul S, Fasting $\mathrm{H}$ et al. Screening for abdominal aortic aneurysms: single centre randomized controlled trial. BMJ 2005; 330: 750-3.

21. Jamrozik K, Norman PE, Spencer CA et al. Screening for abdominal aortic aneurysm: lessons from a population-based study. Med J Aust 2000; 173: $345-50$

22. Cosford PA, Leng GC. Screening for abdominal aortic aneurysm. Cochrane Database Syst Rev 2007: nr. 2. CD002945.

23. Scott RA. The place for screening in the management of abdominal aortic aneurysms. Scand J Surg 2008; 97: 136-8.

24. Lederle FA, Wilson SE, Johnson GR et al: Aneurysm Detection and Management (ADAM) Veterans Affairs Cooperative Study Group. Immediate repai compared with surveillance of small abdominal aortic aneurysms. N Engl J Med 2002; 346: $1437-44$

25. Ballard DJ, Filardo G, Fowkes $G$ et al. Surgery for small asymptomatic abdominal aortic aneurysms. Cochrane Database Syst Rev 2008; nr. 4 CD001835

26. Brown LC, Powell JT. Risk factors for aneurysm rupture in patients kept under ultrasound surveillance. Ann Surg 1999; 230: 289-96.

27. Singh $\mathrm{K}$, Jacobsen BK, Solberg S et al. The difference between ultrasound and computed tomography (CT) measurements of aortic diameter: analysis of axial images of abdominal aortic and common iliac artery diameter in normal and aneurismal aortas. The Troms $\varnothing$ Study, 1994-95. Eur J Vasc Endovasc Surg 2004: 28: 158-67.

28. Swedenborg J. Abdominal aortic aneurysms in the interval 5-5,5 cm, art or evidence? Scand J Surg 2008; 97: 128-30.

29. EVAR trial participants. Endovascular aneurysm repair and outcome in patients unfit for open repair of abdominal aortic aneurysm (EVAR trial 2) randomised controlled trial. Lancet 2005; 365 2187-92.

30. Lederle FA, Johnson GR, Wilson SE et al. Rupture rate of large abdominal aortic aneurysms in patients refusing or unfit for elective repair. JAMA 2002; 287: 2968-72. 